\title{
Endovascular Mechanical Thrombectomy in Basilar Artery Occlusion: Initial Experience
}

\author{
Bum-Soo Park, Chang-Woo Kang, Hyon-Jo Kwon, Seung-Won Choi, Seon-Hwan Kim, Hyeon-Song Koh, \\ Jin-Young Youm, Shi-Hun Song \\ Department of Neurosurgery, School of Medicine, Chungnam National University, Daejeon, Korea
}

Objective : This study was conducted to assess the efficacy and safety of endovascular mechanical thrombectomy (EMT) for patients diagnosed with basilar artery (BA) occlusion.

Materials and Methods: We retrospectively analyzed clinical and imaging data of 16 patients diagnosed with BA occlusion who were treated with endovascular intervention from July 2012 to February 2013. Direct suction using the Penumbra system and thrombus retrieval by the Solitaire stent were the main endovascular techniques used to restore BA flow. The outcomes were evaluated based on rate of angiographic recanalization, rate of improvement of National Institutes of Health Stroke Scale (NIHSS) score, rate of modified Rankin Scale (mRS) at discharge and after 3 months, and rate of cerebral hemorrhagic complications. Successful recanalization was defined as achieving Thrombolysis In Cerebral Infarction (TICI) of II or III.

Results : Sixteen patients received thrombectomy. The mean age was 67.8 \pm 11 years and the mean NIHSS score was $12.3 \pm 8.2$. Eight patients treated within 6 hours of symptom onset were grouped as $A$ and the other 8 patients treated beyond 6 hours (range, 6-120) were grouped as B. Successful recanalization was met in six patients (75\%) for group A and $7(87.5 \%)$ for group B. Favorable outcome occurred in 4 patients (50\%) for group A and 5 (62.5\%) for group B.

Conclusion : Our study supports the effectiveness and safety of endovascular mechanical thrombectomy in treating BA occlusion even 6 hours after symptom onset.

Keywords Basilar artery occlusion, Endovascular mechanical thrombectomy, Therapeutic time window, Recanalization

\author{
J Cerebrovasc Endovasc Neurosurg. \\ 2013 September; 15(3):137-144 \\ Received : 14 June 2013 \\ Revised : 11 July 2013 \\ Accepted : 1 August 2013

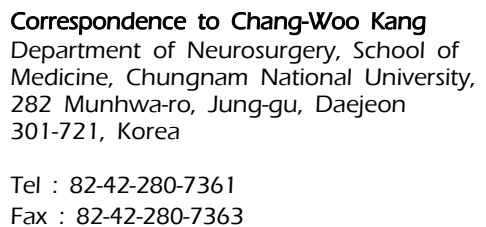

Correspondence to Chang-Woo Kang Department of Neurosurgery, School of Medicine, Chungnam National University, 282 Munhwa-ro, Jung-gu, Daejeon 301-721, Korea

Tel : $82-42-280-7361$

Fax : 82-42-280-7363 \\ E-mail : tbd9900@naver.com
}

This is an Open Access article distributed under the terms of the Creative Commons Attribution NonCommercial License (http://creativecommons.org/licenses/by-nc/3.0) which permits unrestricted noncommercial use, distribution, and reproduction in any medium, provided the original work is properly cited.

\section{INTRODUCTION}

The basilar artery (BA) supplies the brain stem, cerebellum, thalami, occipital lobes and medial temporal lobes. If the BA is occluded, symptoms can include decreased consciousness, quadriparesis, pupillary and oculomotor abnormalities, dysarthria, dysphagia or even sudden death. ${ }^{10)} \mathrm{BA}$ occlusion accounts for about $20 \%$ of ischemic strokes. ${ }^{13)}$ Acute occlusion of this artery produces high morbidity and mortality, with a rate of $85-95 \%$, if left untreated. ${ }^{613221)}$ Without recanalization, the likelihood of good outcome is about $2 \%{ }^{6}{ }^{6}$ The chief goal in treating acute ischemic stroke is to restore cerebral blood flow as rapidly and safely as 

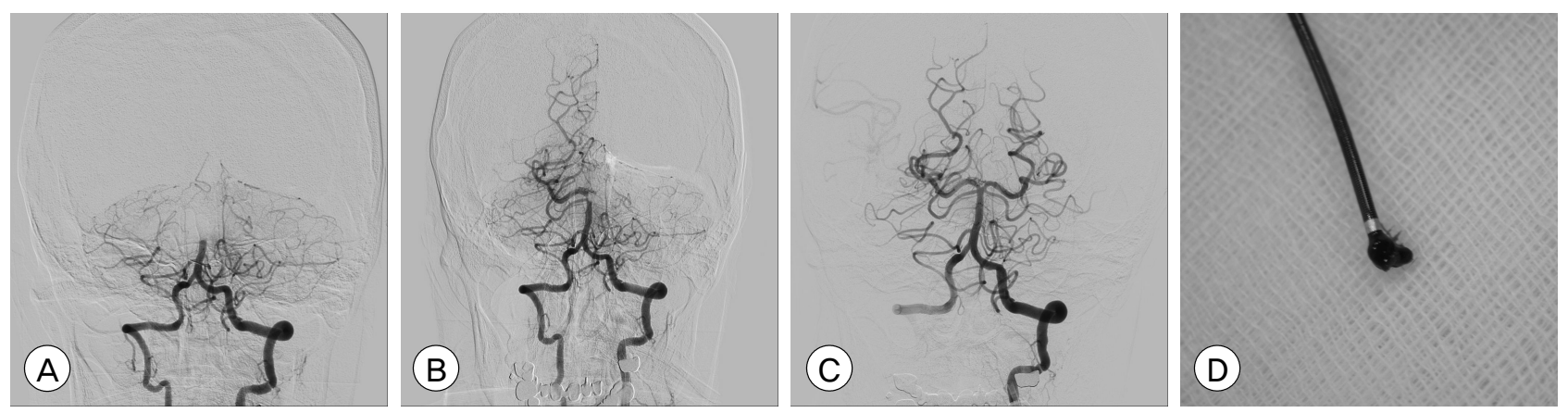

Fig. 1. (A) The angiogram shows occlusion of the basilar artery. (B) After placing the Penumbra system at the occlusion site, suction was performed and partial recanalization is shown. (C) Endovascular mechanical thrombectomy using the Penumbra system was carried out again and follow up angiogram shows complete recanalization. (D) Thrombus is pulled out by the Penumbra system.

possible. ${ }^{14177)}$ Intravenous tissue plasminogen activator (IV-tPA) or endovascular techniques are widely used to produce vascular patency and to improve clinical outcomes. It has become a fairly standard practice in the anterior circulation to set a time restriction to the first 6 hours of symptom onset for endovascular mechanical thrombectomy (EMT) to limit hemorrhagic transformation of infarctions and because of its poor contribution to favorable clinical outcome. ${ }^{15)}$ However, the effective therapeutic time window has not been established for the posterior circulation. ${ }^{16)}$ Therefore, we conducted a study to verify the efficacy and safety of endovascular mechanical thrombectomy for BA occluded patients, even beyond 6 hours of symptom onset.

\section{MATERIALS AND METHODS}

Medical records of 16 consecutive patients who were treated for symptomatic acute BA occlusion from July 2012 to Feb 2013 were reviewed. To rule out hemorrhagic stroke or old infarction, all patients underwent brain-computed tomography (CT) on arrival. Magnetic resonance images (MRI), such as diffusion-weighted image (DWI), MR angiography and perfusion-weighted image (PWI) were then tracked to detect the occluded vessels, DWI-PWI mismatch, and measure infarct territories. Intravenous thrombolysis (IVT) was started with $0.9 \mathrm{mg} / \mathrm{kg}$ IV-tPA when the diagnosis was confirmed within 3 hours of symptom onset. If refractory to IVT or contraindicated or the patients arrived more than 3 hours after symptom onset, EMT was performed. Indications for EMT treatment were a National Institutes of Health Stroke Scale (NIHSS) score of 4 or more, age more than 18 years and arrival at the stroke center beyond 3 hours of symptom onset. Considering these uncertainties and high mortality rate of untreated BA occluded patients, our stroke center adopted a protocol to treat not only patients who came within 6 hours of symptom onset but also who came beyond 6 hours with symptom aggravation, mismatch between DWI and PWI.

All procedures were performed under local anesthesia by an endovascular neurosurgeon. The occlusion status was confirmed by taking angiography after locating the guiding catheter (Guider XF Softip ${ }^{\mathrm{TM}}$, Boston Scientific, Plymouth, MN, USA) to the proximal vertebral artery. To prevent procedural thromboembolic events, a mixture of 2,000 IU of heparin and $0.9 \%$ normal saline $1,000 \mathrm{ml}$ was administered continuously through the guiding catheter. This was applied even to patients who received IV-tPA. The main endovascular techniques used to restore BA flow were direct thrombectomy using the Penumbra thromboaspiration catheter (Penumbra Inc., Alameda, CA, USA) (Fig. 1) and thrombus retrieval by the Solitaire stent (ev3 Inc., Irvine, CA, USA) (Fig. 2). The Penumbra system with microcatheter (Prowler SELECT $^{\mathrm{TM}}$ PLUS, Codman Neurovascular, Raynham, 
MA, USA) and microwire (Synchro $^{\mathrm{TM}}-14$, Stryker Neurovascular, Fremont, CA, USA) were brought into the target vessel and placed at the distal portion of the occlusion site after penetrating the thrombus segment. Using a 50 cc syringe, negative pressure was applied through the Penumbra system. If recanalization failed, the Solitaire stent was used for mechanical thrombectomy. The Solitaire stent was deployed where it could completely cover the occluded segment and left in place for at least 2 minutes before retrieval. The microcatheter and the stent were gently withdrawn together with the guiding catheter while a 50 cc syringe maintained negative pressure through the guiding catheter to aspirate the thrombus and to prevent migration of the emboli. If stenosis of vertebral artery was too severe for catheter entry, balloon angioplasty and stent deployment was performed at the segment and post-balloon was carried out if vascular patency was unsatisfactory. After EMT, the brain was scanned routinely by CT within 1 hour to check for any procedural related intracerebral hemorrhage and by MRI after 24 hours to see any changes in the infarct region.

Neurologic status was recorded based on NIHSS score. The outcome data were collected by: (1) rate of angiographic recanalization; (2) rate of improvement of NIHSS score and mRS at discharge and after 3 months; and (3) rate of cerebral hemorrhagic complications such as symptomatic hemorrhages or paren- chymal hematomas, measured to evaluate the safety of EMT. Successful recanalization was defined as achieving TICI II (partial recanalization) or III (complete recanalization) ${ }^{18)}$ Assessment of the modified Rankin Scale (mRS) was performed 90 days after treatment. A mRS of 0 to 2 was defined as a good neurological outcome. To assess the efficacy and safety of EMT performed after 6 hours, patients were assigned to 2 groups. Group A was defined as patients treated within 6 hours of symptom onset and group B as those treated beyond 6 hours. The data from these studies were statistically analyzed using the SPSS version 20. (IBM Corp., Armonk, NY, USA). Statistical procedures included Student's t-test and Pearson's chi-square as appropriate for continuous or categorical variables. Null hypotheses of no difference were rejected if $p$ values were less than 0.05 .

\section{RESULTS}

Of the 16 consecutive patients with BA occlusion treated mainly with EMT from July 2012 to Feb 2013, 12 were men and 4 were women, with a mean age of $67.8 \pm 11$ years. The median symptom-to-puncture time was 5.8 hours (range, 3-120). In initial conventional angiography, proximal thrombosis was present in $50 \%$ and middle and distal basilar thrombosis in the remaining $50 \%$. Four patients (case number 1, 2, $6,14)$ who came to our stroke center within 3 hours
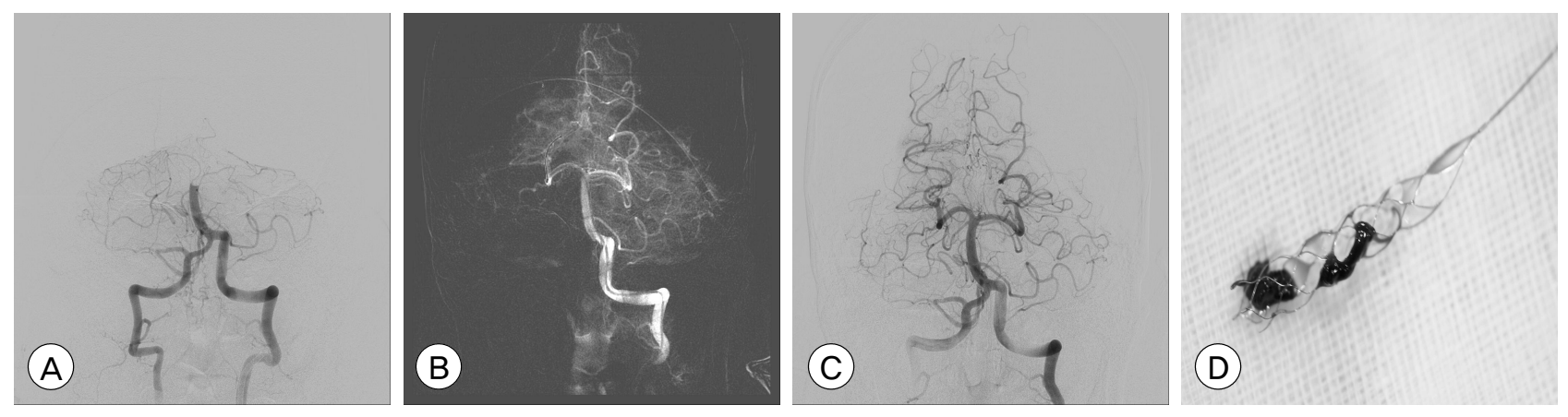

Fig. 2. (A) Initial angiogram in the anteroposterior plane shows basilar artery occlusion (thrombolysis in cerebral infarction grade 0). (B) Cerebral angiogram after temporary deployment of the Solitaire stent shows sufficient coverage and transient flow restoration of the occluded segment. (C) After retrieval of the stent, complete recanalization is shown. (D) Thrombus is trapped by the stent. 
Table 1. Demographic characteristics

\begin{tabular}{|c|c|c|c|c|c|c|c|c|c|c|c|c|c|c|c|}
\hline Case & Age & Sex & $\begin{array}{c}\text { Vascular } \\
\text { risk } \\
\text { factors }\end{array}$ & $\begin{array}{l}\text { Initial } \\
\text { NIHSS }\end{array}$ & $\begin{array}{l}\text { Occlusion } \\
\text { site }\end{array}$ & $\begin{array}{l}\text { IV-tPA } \\
\text { dose } \\
\text { (mg) }\end{array}$ & $\begin{array}{l}\text { Onset to } \\
\text { puncture } \\
\text { time (min) }\end{array}$ & $\begin{array}{l}\text { NIHSS } \\
\text { (D/C) }\end{array}$ & $\begin{array}{l}\mathrm{mRS} \\
\text { (D/C) }\end{array}$ & $\begin{array}{l}\text { 3mo- } \\
\text { mRS }\end{array}$ & TOAST & $\begin{array}{c}\text { PcoA } \\
\text { existence }\end{array}$ & $\mathrm{TICl}$ & $\begin{array}{l}\text { Hemorrhagic } \\
\text { infarction }\end{array}$ & $\begin{array}{c}\text { Procedure } \\
\text { time } \\
\text { (min) }\end{array}$ \\
\hline 1 & 83 & $\mathrm{~F}$ & 2 & 10 & Proximal & 50 & 190 & 7 & 5 & 5 & LAA & No & 1 & Yes & 109 \\
\hline 2 & 76 & $M$ & 4 & 16 & Distal & 67.5 & 192 & 36 & 6 & 6 & LAA & Yes & 1 & No & 120 \\
\hline 3 & 76 & $\mathrm{~F}$ & 4 & 6 & Proximal & $\mathrm{n} / \mathrm{a}$ & 219 & 17 & 5 & 5 & CE & Yes & lla & Yes & 61 \\
\hline 4 & 52 & $M$ & 2 & 24 & Distal & $\mathrm{n} / \mathrm{a}$ & 220 & 2 & 1 & 1 & LAA & No & Ila & No & 78 \\
\hline 5 & 82 & $M$ & 4 & 15 & Distal & $\mathrm{n} / \mathrm{a}$ & 255 & 5 & 3 & 2 & CE & Yes & III & Yes & 56 \\
\hline 6 & 84 & M & 1 & 11 & Proximal & 70 & 277 & 4 & 3 & 1 & LAA & No & III & Yes & 91 \\
\hline 7 & 56 & $\mathrm{~F}$ & 2 & 9 & Distal & $\mathrm{n} / \mathrm{a}$ & 287 & 0 & 0 & 0 & LAA & Yes & III & No & 28 \\
\hline 8 & 55 & M & 1 & 12 & Proximal & $\mathrm{n} / \mathrm{a}$ & 335 & 10 & 5 & 5 & LAA & Yes & III & No & 85 \\
\hline 9 & 71 & M & 3 & 8 & Distal & $\mathrm{n} / \mathrm{a}$ & 363 & 3 & 1 & 1 & CE & No & III & No & 65 \\
\hline 10 & 74 & $M$ & 0 & 13 & Proximal & $\mathrm{n} / \mathrm{a}$ & 365 & 13 & 5 & 5 & LAA & Yes & Ila & Yes & 137 \\
\hline 11 & 60 & M & 2 & 7 & Distal & $\mathrm{n} / \mathrm{a}$ & 653 & 0 & 0 & 0 & LAA & Yes & Ila & No & 147 \\
\hline 12 & 61 & $M$ & 1 & 19 & Distal & $\mathrm{n} / \mathrm{a}$ & 682 & 6 & 4 & 3 & LAA & No & III & No & 74 \\
\hline 13 & 54 & $M$ & 3 & 34 & Proximal & $\mathrm{n} / \mathrm{a}$ & 1088 & 34 & 5 & 5 & LAA & Yes & 0 & No & 132 \\
\hline 14 & 75 & $M$ & 2 & 6 & Proximal & 72 & 1235 & 5 & 4 & 2 & LAA & Yes & III & Yes & 205 \\
\hline 15 & 63 & $M$ & 2 & 1 & Proximal & $\mathrm{n} / \mathrm{a}$ & 4691 & 1 & 1 & 0 & LAA & No & lla & No & 119 \\
\hline 16 & 63 & $\mathrm{~F}$ & 1 & 5 & Distal & $\mathrm{n} / \mathrm{a}$ & 6933 & 1 & 1 & 0 & LAA & No & lla & No & 45 \\
\hline
\end{tabular}

NIHSS= National Institutes of Health Stroke Scale; IV-tPA= intravenous tissue plasminogen activator; mRS= modified Rankin Scale; $\mathrm{D} / \mathrm{C}=$ discharge; TOAST= Trial of Org 10172 in Acute Stroke Treatment; PcoA= posterior communicating artery; $\mathrm{TICl}=$ thrombolysis in cerebral infarction; $n / a=$ not available; $L A A=$ large-artery atherosclerosis; $C E=$ cardioembolism.

of symptom onset were treated with IVT. They presented with gradual aggravation of symptoms and received EMT. The other 12 patients depended on EMT as a first-line treatment (Table 1). The most commonly diagnosed cardiovascular co-morbidities were hypertension $(75 \%)$, type 2 diabetes $(43.8 \%)$, previous stroke $(25 \%)$ and atrial fibrillation (18.8\%). The major etiologic risk factors were large artery atherosclerosis (81.2\%) followed by cardioembolism (18.8\%) (Table 2).

Three patients $(18.8 \%)$ were unconscious and needed respiratory support to maintain adequate ventilation, while 1 patient died, a mortality rate was $6.2 \%$. Of the 16 patients, revascularization was achieved in 13 (81.3\%) (TICI grade IIa/IIB and III). The mean initial NIHSS score was $12.3 \pm 8.2$ and mean NIHSS score at discharge was $9 \pm$ 11.2. In 7 patients (43.7\%), NIHSS scores improved more than 10 or were $0-1$ at the time of discharge. At 3 months, $56.3 \%$ (9 of 16) of patients had a good neurologic outcome (mRS 0-2) (Table 3). Eight patients who were treated within 6 hours of symptom onset were grouped as A.
Of those patients recanalization (TICI II or III) was achieved in 6 patients $(75 \%)$ and $4(50 \%)$ had good outcomes. The other 8 patients were treated with EMT after 6 hours and were grouped as B. Successful recanalization was achieved in 7 patients $(87.5 \%)$ and $5(62.5 \%)$ had favorable outcomes. The mean puncture

Table 2. Patient characteristics

\begin{tabular}{ll}
\hline Characteristic & 16 \\
\hline $\begin{array}{l}\text { Number of patients } \\
\text { Demographic data } \\
\text { Mean age, (Range) }\end{array}$ & $67.8(52-84)$ \\
Male : Female & $12: 4$ \\
Risk factors, $\mathrm{n},(\%)$ & \\
Hypertension & $12(75)$ \\
Type 2 diabetes & $7(43.8)$ \\
Previous stroke & $4(25)$ \\
Atrial fibrillation & $3(18.8)$ \\
Site of occlusion, $\mathrm{n},(\%)$ & $8(50)$ \\
Proximal & $8(50)$ \\
Middle or distal &
\end{tabular}


Table 3. Radiological and clinical outcomes

\begin{tabular}{|c|c|}
\hline Outcomes & \\
\hline \multicolumn{2}{|l|}{ Success rate of recanalization, $\mathrm{n}(\%)$} \\
\hline Complete recanalization (TICI III) & 7 (43.7) \\
\hline Partial recanalization (TICI IIa/IIb) & $6(37.5)$ \\
\hline Recanalization failure ( $\mathrm{TICl} 0 / \mathrm{I})$ & $3(18.7)$ \\
\hline \multicolumn{2}{|l|}{ NIHSS score, mean } \\
\hline Initial & $12.3 \pm 8.2$ \\
\hline At discharge & $9 \pm 11.2$ \\
\hline \multicolumn{2}{|l|}{ Improvement of clinical symptom, n (\%) } \\
\hline Complete improvement (NIHSS $=0$ ) & $2(12.5)$ \\
\hline Marked improvement (NIHSS $\geq 10$ or NIHSS $=1$ ) & $5(31.2)$ \\
\hline $\mathrm{mRS} \leq 2$ at 3 months & $9(56.3)$ \\
\hline
\end{tabular}

NIHSS= National Institutes of Health Stroke Scale; mRS= modified Rankin Scale; $\mathrm{TICl}=$ thrombolysis in cerebral infarction.

to recanalization time was $97 \pm 45.2$ minutes. It took a mean of $78.5 \pm 29.8$ minutes for group $A$ and 115.5 \pm 52 minutes for group B. Following EMT, 4 patients (50\%) had asymptomatic hemorrhagic transformation in group A and 2 (25\%) in group B (Table 4).

\section{DISCUSSION}

\section{Cause and natural history of BA occlusion}

BA occlusion is an uncommon disease that accounts for about $20 \%$ of ischemic strokes. ${ }^{13)}$ Common co-morbidities for BA occlusion include atherosclerosis followed by embolism, dissections, aneurysm, migraine and inflammatory conditions. ${ }^{20)}$ Patients with cardiogenic thromboembolism tended to have worse GCS score and NIHSS than those with artherothrombotic occlusion. ${ }^{3) 7}$ The rate of spontaneous reopening in basilar artery occlusion is thought to be less than $20 \%$ and middle cerebral artery (MCA) occlusion can be expected in 30 to $60 \% .{ }^{17}$ ) The prognosis of BA occlusion is poor with mortality ranging from $85 \%$ to 95\%. ${ }^{13) 17)}$ Compared with $41 \%$ to $79 \%$ mortality of nonrecanalizers of malignant MCA infarction, BA occlusion has a very high fatality risk. ${ }^{8) 19)}$

\section{Treatment modalities of BA occlusion}

Early recanalization is the key to treat hyperacute cerebral infarction. ${ }^{1) 4) 17)}$ Several treatment modalities have been introduced to maximize the efficacy of reversing the occlusion. One is IVT, which has become a standard treatment of acute stroke. IV-tPA has been approved for a time window of 3 hours. ${ }^{15)}$ Intraarterial thrombectomy (IAT) is chosen when IVT is contraindicated or found ineffective. In the Penumbra pivotal study, the recanalization rate (TIMI 2/3) was $81 \%$, the rate of NIHSS score improvement by more than 10 or checked $0-1$ at discharge was $27 \%$ and 3 month mRS $\leq 2$ was $25 \% .{ }^{12)}$ Roth et al. ${ }^{17)}$ reported that the recanalization rate of thrombectomy using the Solitaire stent was $90.9 \%$, improvement of NIHSS score by more than 10 was $63.6 \%$ and at discharge and 3 month mRS $\leq 2$ both were $50 \%$. Considering multiple case series and preliminary data, they suggested that recanalization rates were higher with EMT than with IVT or IAT.

Our study employed widely used devices, the Penumbra system and the Solitaire stent for MT to treat BA occlusion. The recanalization rate of EMT in our hospital was $81.2 \%$, the average NIHSS score improved by more than 10 or confirmed $0-1$ at discharge was $43.7 \%$ and $56.2 \%$ of patients had a good neurologic outcome $(3$ month $\mathrm{mRS} \leq 2)$. Lindsberg et al. $\left.{ }^{10}\right)$ analyzed and compared systematically the studies of IVT and IAT in BA occlusion, finding that recanalization rate for IVT was $53 \%$ and for IAT $65 \%$. A total 
Table 4. Comparison of patient groups

\begin{tabular}{cccccccc}
\hline Group & $\begin{array}{c}\text { Age } \\
\text { (y) }\end{array}$ & $\begin{array}{c}\text { Recanalization } \\
(\%)\end{array}$ & $\begin{array}{c}\text { NIHSS improvement } \\
\text { (\%) }\end{array}$ & $\begin{array}{c}\text { 3-mo mRS } \leq 2 \\
\text { (\%) }\end{array}$ & $\begin{array}{c}\text { Complication } \\
\text { (\%) }\end{array}$ & $\begin{array}{c}\text { Mortality } \\
\text { (\%) }\end{array}$ & $\begin{array}{c}\text { Procedure time } \\
\text { (min) }\end{array}$ \\
\hline A & 70.5 & 75 & 37.5 & 50 & 50 & 1.25 \\
B & 65.1 & 87.5 & 50 & 62.5 & 25 & 0 \\
\hline
\end{tabular}

Group A: endovascular mechanical thrombectomy within 6 hours of symptom onset, group B: endovascular mechanical thrombectomy after 6 hours of symptom onset, NIHSS= National Institutes of Health Stroke Scale; mRS= modified Rankin Scale.

of $22 \%$ of patients treated with IVT and $24 \%$ treated with IAT reached good outcomes. Compared with the effect of IVT and IAT, our EMT showed a better recanalization rate and clinical results. EMT can rapidly and effectively restore BA flow and improve patients' outcomes. Therefore, EMT should be regarded as an alternative treatment to IAT if IVT is contraindicated or ineffective.

\section{EMT after 6 hours}

It has been a standard practice to set a time restriction for MT to the first 6 hours of symptoms for the occlusion of anterior circulation. ${ }^{15)}$ The Literature tends to elongate the time limit for BA occlusion and the extension benefitted many patients. ${ }^{11)}$ There are several reports of patients with BA occlusion who had successful recanalization and good functional outcomes with thrombolysis up to 79 hours after symptom onset and with endovascular mechanical clot retraction up to 36 hours after onset. ${ }^{211) 21)}$ Because prognosis in untreated patients is extremely poor, and theoretical assumptions and clinical observations agree that the brainstem is more tolerant of longer periods of ischemia than the cerebral hemispheres, there is support for idea of extending the window for thrombolytic and endovascular therapy in specific cases. ${ }^{11)}$ In our series, 8 patients received EMT beyond 6 hours of symptom onset with recanalization rate of $85.7 \%$ and good outcomes in 5 patients (62.5\%). Furthermore, extending the time limit did not increase the risk of hemorrhagic transformation. Therefore, longer time limits for BA occlusion treatment should be considered.

\section{Prognostic factors for favorable clinical outcome}

There are many variables contributing to patient prognosis. Affecting functional outcome are age, vascular risk factors such as atrial fibrillation, initial NIHSS score, treatment time window, presence of collateral flow, occlusion site, presenting course and recanalization. ${ }^{914)}$ Our study demonstrated an intimate relationship between occlusion site and prognosis. It took less time to recanalize the distal occlusion (mean, $76.6 \pm 39.2$ minutes) compared with the proximal ones (mean, $117.3 \pm 43$ minutes) $(p<0.05)$. Distal occlusion had more favorable outcome (75\%) than proximal $(37 \%)(p<0.05)$. Cross et al. $\left.{ }^{5}\right)$ reported that distal basilar thrombosis tended to be embolic, while proximal tended to be the result of atherosclerosis and the outcome was better after intra-arterial thrombolysis in patients who had occlusion middle or distal portion of basilar artery than that of the proximal ones. Lindsberg et al. ${ }^{10)}$ also reported that the distal, typically embolic occlusions recanalize more easily than the more proximal ones. In conclusion, distal occlusions having embolic entities are easier to recanalize resulting in a favorable outcome.

\section{Technical factor}

In addition, if the vessel is tortuous or vertebral artery os is severely stenosed, approach to the occlusion site and maneuver of catheter or stent is difficult. It requires more time, greater number of runs and higher expertise to achieve recanalization and entails a higher risk of procedural related complications such as arterial rupture or dissection. One patient who had a severe stenosis at the os of vertebral artery underwent balloon angioplasty in an attempt to widen the caliber. Because of inadequate dilatation of vessel diameter, we decided to deploy a stent to the segment. 
Due to an unstable guiding catheter, we failed to deploy the stent to the lesion, and the narrow and tortuous vessel disturbed our further catheter maneuver and hindered our reaching the occlusion site of basilar artery. Another case who had a tortuous vessel took a long time for the procedure. Newly formed thrombi kept appearing in the angiography. Although partial recanalization succeeded, recurrent obstruction by the thrombi deterred our treatment. There are many variables influencing the recanalization rate of EMT so further study is needed to gain a better understanding and to improve the efficacy of EMT for a better outcome.

\section{CONCLUSION}

If a basilar artery occlusion is left untreated, the prognosis is extremely poor. Therefore, it is important to reverse the occluded artery for a better outcome. Our study suggests that endovascular mechanical thrombectomy has advantage of prompt flow restoration with the potential for a good outcome, even beyond 6 hours of symptom onset. Further studies with larger sample size and a longer duration are needed to support this idea.

\section{REFERENCES}

1. Andersson T, Kuntze Soderqvist A, Soderman M, Holmin S, Wahlgren N, et al. Mechanical thrombectomy as the primary treatment for acute basilar artery occlusion: Experience from 5 years of practice. J Neurointerv Surg. 2013 May;5(3):221-5.

2. Bergui M, Stura G, Daniele D, Cerrato P, Berardino M, Bradac GB. Mechanical thrombolysis in ischemic stroke attributable to basilar artery occlusion as first-line treatment. Stroke. 2006 Jan;37(1):145-50.

3. Chandra RV, Law CP, Yan B, Dowling RJ, Mitchell PJ. Glasgow coma scale does not predict outcome post-intra-arterial treatment for basilar artery thrombosis. AJNR Am J Neuroradiol. 2011 Mar;32(3):576-80.

4. Clarencon F, Blanc R, Gallas S, Hosseini H, Gaston A. Thrombectomy for acute basilar artery occlusion by using double Merci retriever devices and bilateral temporary vertebral artery flow reversal. Technical note. J Neurosurg. 2009 Jul;111(1):53-6.
5. Cross DT 3rd, Moran CJ, Akins PT, Angtuaco EE, Derdeyn CP, Diringer MN. Collateral circulation and outcome after basilar artery thrombolysis. AJNR Am J Neuroradiol. 1998 Sep;19(8):1557-63.

6. Grigoriadis S, Gomori JM, Grigoriadis N, Cohen JE. Clinically successful late recanalization of basilar artery occlusion in childhood: What are the odds? Case report and review of the literature. J Neurol Sci. 2007 Sep;260(1-2):256-60.

7. Kashiwagi J, Kiyosue H, Hori Y, Okahara M, Tanoue S, Sagara $Y$, et al. Endovascular recanalization of acute intracranial vertebrobasilar artery occlusion using local fibrinolysis and additional balloon angioplasty. Neuroradiology. 2010 May;52(5):361-70.

8. Lee CY, Ryu CW, Koh JS, Kim GK. Late spontaneous recanalization of chronic middle cerebral artery occlusion. Neurointervention. 2012 Sep;7(2):113-6.

9. Lindsberg PJ, Mattle HP. Therapy of basilar artery occlusion: A systematic analysis comparing intra-arterial and intravenous thrombolysis. Stroke. 2006 Mar;37(3):922-8.

10. Mattle HP, Arnold M, Lindsberg PJ, Schonewille WJ, Schroth G. Basilar artery occlusion. Lancet Neurol. 2011 Nov;10(11):1002-14.

11. Noufal M, Schmidley JW, Erdem E, Keyrouz SG. Basilar artery occlusion treated with mechanical thrombectomy beyond eight hours with successful recanalization and good functional outcomes. Cerebrovasc Dis. 2009;27(6):614-5.

12. Penumbra Pivotal Stroke Trial Investigators. The penumbra pivotal stroke trial: Safety and effectiveness of a new generation of mechanical devices for clot removal in intracranial large vessel occlusive disease. Stroke. 2009 Aug;40(8):2761-8.

13. Lindsberg PJ, Soinne L, Tatlisumak T, Roine RO, Kallela $\mathrm{M}$, Happola $\mathrm{O}$, et al. Long-term outcome after intravenous thrombolysis of basilar artery occlusion. JAMA. 2004 Oct;292(15):1862-6.

14. Pfefferkorn T, Holtmannspotter M, Schmidt C, Bender A, Pfister HW, Straube A, et al. Drip, ship, and retrieve: Cooperative recanalization therapy in acute basilar artery occlusion. Stroke. 2010 Apr;41(4):722-6.

15. Pfefferkorn T, Mayer TE, Opherk C, Peters N, Straube A, Pfister HW, et al. Staged escalation therapy in acute basilar artery occlusion: Intravenous thrombolysis and on-demand consecutive endovascular mechanical thrombectomy: Preliminary experience in 16 patients. Stroke. 2008 May;39(5):1496-500.

16. Roth C, Mielke A, Siekmann R, Ferbert A. First experiences with a new device for mechanical thrombectomy in acute basilar artery occlusion. Cerebrovasc Dis. 2011;32(1):28-34.

17. Smith WS. Intra-arterial thrombolytic therapy for acute basilar occlusion: Pro. Stroke. 2007 Feb;38(2 Suppl):701-3.

18. Smith WS, Sung G, Saver J, Budzik R, Duckwiler G, Liebeskind DS, et al. Mechanical thrombectomy for acute ischemic stroke: Final results of the Multi MERCI trial. Stroke. 2008 Apr;39(4):1205-12.

19. Vahedi K, Hofmeijer J, Juettler E, Vicaut E, George B, Algra A, et al. Early decompressive surgery in malignant infarction of the middle cerebral artery: A pooled 
ENDOVASCULAR MECHANICAL THROMBECTOMY IN BA OCCLUSION

analysis of three randomised controlled trials. Lancet Neurol. 2007 Mar;6(3):215-22.

20. Voetsch B, DeWitt LD, Pessin MS, Caplan LR. Basilar artery occlusive disease in the New England Medical
Center Posterior Circulation Registry. Arch Neurol. 2004 Apr;61(4):496-504.

21. Yu W, Kostanian V, Fisher M. Endovascular recanalization of basilar artery occlusion 80 days after symptom onset. Stroke. 2007 Apr;38(4):1387-9. 